\title{
254C>G: a TRPC6 promoter variation associated with enhanced transcription and steroid-resistant nephrotic syndrome in Chinese children
}

\author{
Xin-Yu Kuang ${ }^{1}$, Wen-Yan Huang ${ }^{2}$, Hong Xu' ${ }^{1}$ Yu Shi', Xiu-Ling Zhang ${ }^{1}$, Xiao-Ling Niu' ${ }^{2}$, Ying Wu ${ }^{2}$, Chuan-Zhong Mei ${ }^{3}$, \\ Xi-Liang Zha ${ }^{3}$, Zhong-Hua Zhao ${ }^{4}$ and Zhi-Gang Zhang ${ }^{4}$
}

\begin{abstract}
BACKGROUND: Mutations in canonical transient receptor potential channel 6 (TRPC6) have been identified as responsible for the development of focal segmental glomerulosclerosis, a proteinuric disease with steroid resistance and poor prognosis. This study explores the prevalence of TRPC 6 variants in Chinese children with idiopathic nephrotic syndrome (INS), the genotype/phenotype correlation of TRPC6 variants, the therapeutic response, and the underlying molecular mechanism.
\end{abstract}

METHODS: Fifty-one children with sporadic INS were enrolled: 23 steroid-sensitive cases and 28 steroid-resistant cases. Polymerase chain reaction was used to amplify 13 exons and the promoter sequences of TRPC 6 before sequencing. The expression of TRPC6 in renal tissues was illustrated by immunohistochemistry staining. The transcriptional activity of variants in TRPC6 promoter was measured by the luciferase assay.

RESULTS: Three variants $(-254 \mathrm{C}>\mathrm{G}$, rs3824934; +43C/T, rs3802829; and $240 \mathrm{G}>\mathrm{A}$, rs17096918) were identified. The allele frequency of the -254C>G single-nucleotide polymorphism (SNP) in the steroid-resistant nephrotic syndrome (SRNS) patients (40.5\%) was higher than that in the steroid-sensitive nephrotic syndrome subjects $(27.1 \% ; P=0.046)$. The $-254 C>G$ SNP enhanced transcription from TRPC6 promoter in vitro and was associated with increased TRPC6 expression in renal tissues of SRNS patients.

CONCLUSION: -254C>G, a SNP underlying enhanced TRPC6 transcription and expression, may be correlated with the development of steroid resistance in Chinese children with INS.

diopathic nephrotic syndrome (INS) is a group of proteinuric disorders with a heterogeneous pathogenesis. The histological features range from minimal change nephrotic syndrome to focal segmental glomerulosclerosis (FSGS), with variable responses to glucocorticoids, the mainstay antiproteinuria treatment (1). FSGS is a major cause of proteinuria and renal failure (2). It is responsible for 5-20\% of all cases of end-stage kidney disease in the USA, and besides urogenital and kidney malformations, it is the main cause of end-stage kidney disease in children (2-4). Approximately $90 \%$ of the pediatric INS cases are steroid responsive (steroid-sensitive nephrotic syndrome (SSNS)), and 10\% of the cases account for steroidresistant nephrotic syndrome (SRNS) (5). Glucocorticoid resistance is an important risk factor for the poor outcome and development of end-stage renal disease within $5 \mathrm{y}(6,7)$.

Mutations in genes encoding podocyte proteins, such as NPHS1, NPHS2, ACTN4, CD2AP, PLCE1, and TRPC6 $(8,9)$, have been identified in patients with SRNS. These proteins have been proven essential for the signaling initiated from the slit diaphragm, which is the key component of the glomerular filtration barrier (10). Therefore, these mutations may contribute to disrupted filtration function and increased protein permeability. The genetic defects found in podocytes provide a better understanding of the pathogenesis of INS and their poor therapeutic responses $(11,12)$. In addition, these gene mutations have been shown to be associated with a reduced incidence of relapse of proteinuria upon renal transplantation (13). One of these proteinuria candidate genes, canonical transient receptor potential channel 6 (TRPC6), encodes TRPC6 protein, a $\mathrm{Ca}^{2+}$-permeable nonselective cation channel, which is a member of the transient receptor potential channel subfamily (10). In 2005, Winn et al. first identified TRPC6 variants segregated with the development of familial FSGS. They also found that TRPC6 was selectively highly expressed in glomerular podocytes $(8,14)$ and localized to the slit diaphragm complex in close association with nephrin and podocin (14). Until now, 13 TRPC6 mutations have been identified in 9 pedigrees (British, African American, Mexico, Irish/German, European/ Indian, Western European, Turkish, and Italian) and sporadic cases of FSGS (Spanish, Turkish, and Italian). Patients carrying TRPC6 mutations seem to progress to end-stage renal failure within 10 y $(8,14-18)$. However, the epidemiologic features of TRPC6 variants in Chinese pediatric INS have not yet been explored. Assuming that the identification of TRPC6

\footnotetext{
'Department of Nephrology and Rheumatology, Children's Hospital of Fudan University, Shanghai, China; ${ }^{2}$ Department of Nephrology and Rheumatology, Children's Hospital of Shanghai, Children's Hospital of Shanghai Jiaotong University, Shanghai, China; ${ }^{3}$ Department of Biochemistry and Molecular Biology, Shanghai Medical College of Fudan University, Shanghai, China; ${ }^{4}$ Department of Pathology, Shanghai Medical College of Fudan University, Shanghai, China. Correspondence: Wen-Yan Huang (huangwy65@gmail.com) 
mutations may provide a rationale for therapeutic choice and prognosis prediction, the purpose of this study is to explore the prevalence of TRPC6 variants in Chinese pediatric INS and to investigate the correlation between the TRPC6 genotype and the therapeutic response.

\section{RESULTS}

\section{Clinicopathological Correlations}

SSNS children were older at disease onset than those with SRNS (5.11 vs. 3.38 y; $P=0.047$ ). The remainders of the demographic and clinical findings are shown in Table 1. As shown by histopathological analysis, minimal change nephrotic syndrome was significantly more common in the SSNS cases, and FSGS was predominant in the SRNS cases.

\section{Genotype/Phenotype Association of the TRPC6 Variants}

We identified three variants in our study: $-254 \mathrm{C}>\mathrm{G}$ ( $\mathrm{rs3824934)}$ in the promoter region, $43 \mathrm{C}>\mathrm{T}(\mathrm{rs} 3802829)$ in exon 1 , and 240 $\mathrm{G}>\mathrm{A}$ (rs17096918) in the exon1-intron1 boundary (Figure 1). The frequency of the $\mathrm{G}$ allele of $-254 \mathrm{C}>\mathrm{G}$ was significantly higher in SRNS than that in SSNS $(P=0.046)$, whereas the frequencies of the $\mathrm{C}$ allele of $\mathrm{P} 15 \mathrm{~S}$ and the A allele of $240 \mathrm{G}>\mathrm{A}$ were similar in both SSNS and SRNS $(P=1.00$ and $P=0.12$, respectively) (Table 2 ). Genotype analyses were conducted for the dominant model, the recessive model, and the additive

Table 1. Clinical characteristics of SSNS and SRNS children

\begin{tabular}{|c|c|c|c|}
\hline Characteristic & SSNS & SRNS & $P$ value \\
\hline$N$ & 23 & 28 & - \\
\hline Gender (M:F) & $19: 4$ & $19: 9$ & - \\
\hline Age of onset (y) & $5.11 \pm 0.61$ & $3.38 \pm 0.59$ & 0.048 \\
\hline BMI & $19.12 \pm 0.60$ & $19.90 \pm 0.84$ & 0.47 \\
\hline Systolic BP (mm Hg) & $101.4 \pm 2.04$ & $107.4 \pm 3.01$ & 0.123 \\
\hline Diastolic BP (mm Hg) & $65.40 \pm 1.63$ & $70.22 \pm 2.49$ & 0.123 \\
\hline Serum creatinine $(\mu \mathrm{mol} / \mathrm{l})$ & $34.73 \pm 4.85$ & $39.84 \pm 5.05$ & 0.502 \\
\hline $\begin{array}{l}\text { Serum urea nitrogen } \\
(\mathrm{mmol} / \mathrm{l})\end{array}$ & $5.478 \pm 1.07$ & $5.891 \pm 0.83$ & 0.76 \\
\hline Blood albumin (g/l) & $22.93 \pm 2.37$ & $20.96 \pm 2.46$ & 0.57 \\
\hline Cholesterol (mmol/l) & $9.38 \pm 0.97$ & $11.0 \pm 1.47$ & 0.324 \\
\hline 24-h Urine protein (g/l) & $2.34 \pm 0.44$ & $4.39 \pm 1.31$ & 0.148 \\
\hline eGFR $\left(\mathrm{ml} \mathrm{min} \mathrm{mi}^{-1} 1.73 \mathrm{~m}^{-2}\right)$ & $177.1 \pm 15.53$ & $144.6 \pm 12.25$ & 0.104 \\
\hline Pathologic types $(n)$ & 13 & 24 & - \\
\hline $\begin{array}{l}\text { Minimal change } \\
\text { nephrotic syndrome }\end{array}$ & 11 & 12 & 0.038 \\
\hline $\begin{array}{l}\text { Focal proliferative } \\
\text { glomerulonephritis }\end{array}$ & 1 & 2 & 0.946 \\
\hline $\begin{array}{l}\text { Focal segmental } \\
\text { glomerulosclerosis }\end{array}$ & 0 & 7 & 0.038 \\
\hline $\begin{array}{l}\text { Membranoproliferative } \\
\text { glomerulonephritis }\end{array}$ & 1 & 3 & 1.0 \\
\hline \multicolumn{4}{|c|}{$\begin{array}{l}\text { BMI, body mass index: weight/height²; BP, blood pressure; eGFR, estimated glomerular } \\
\text { filtration rate (baseline); SRNS, steroid-resistant nephrotic syndrome; SSNS, steroid- } \\
\text { sensitive nephrotic syndrome. }\end{array}$} \\
\hline Data are mean $\pm S D$ & & & \\
\hline
\end{tabular}

model. The $-254 \mathrm{C}>\mathrm{G}$ genotype conferred a greater than threefold increase in the risk of SRNS (dominant model; odds ratio: 3.27; 95\% confidence interval: 1.00-10.69; $P=0.046$; Table 3).

\section{$-254 \mathrm{C}>\mathrm{G}$ Variant in the TRPC6 Promoter Enhanced TRPC6 Transcription}

$-254 \mathrm{C}>\mathrm{G}$ localizes to the promoter region of TRPC6 and its frequency is significantly higher in SRNS patients. P15S localizes near the promoter region of TRPC6. To explore whether these two variations affect the transcription of TRPC6, we compared the transcription activity of these two variants with the wild-type sequence using a dual-luciferase reporter assay. $-254 \mathrm{G}$ allele significantly enhanced the activity of TRPC6 promoter compared with the $43 \mathrm{~T}$ allele $(P=0.008)$ and wild-type allele $(P=0.001)$. There was no significant difference between the $43 \mathrm{~T}$ and wild-type alleles (Figure 2).

\section{-254C>G-driven Upregulation of TRPC6 Correlates With the Development of SRNS}

TRPC6 was ubiquitously expressed in the glomeruli and tubules, including the glomerular epithelium, mesangial cells, tubular interstitial area, and vessels (Figure 3a and Supplementary Figure S1 online). TRPC6 was more highly expressed in SRNS tissues than in SSNS tissues $(P=0.01$; Figure $3 b)$. The SRNS cases with the $-254 \mathrm{G}$ allele showed higher expression of TRPC6 than the cases with the $-254 \mathrm{C}$ allele $(P=0.047$; Figure $3 \mathrm{c}$; Table 4). A similar, nonsignificant trend was found in the SSNS cases $(P=0.11$; Figure $3 c$; Table 4$)$.

\section{DISCUSSION}

The impact of the TRPC6 mutations on the FSGS progress and therapeutical response has been well established and extensively investigated, both in adults and in children. For example, Q889K, M132T, L780P, H218L, and R895L variants of TRPC6 have been identified in different populations, including FSGS and SRNS (15-18). However, the prevalence of TRPC6 mutations and the genotype/phenotype correlation in pediatric INS in China have not been illustrated. The aim of this study is to investigate the TRPC6 mutations in sporadic INS in Chinese children and to provide more information concerning the genetic mechanisms underlying the development of the disease and the resistance to therapy mediated by TRPC6 gene defects.

We identified three variants, $-254 \mathrm{C}>\mathrm{G}, 43 \mathrm{C}>\mathrm{T}$, and $240 \mathrm{G}>\mathrm{A}$, in our group of SSNS and SRNS cases (Figure 1). The allele frequency of the $-254 \mathrm{G}$ allele was higher in SRNS cases, whereas the allele frequencies of the other two single-nucleotide polymorphisms (SNPs) were comparable between the two groups (Table 2). The high frequency of the $-254 \mathrm{G}$ allele in SRNS cases indicates its potential significance in the pathogenesis of steroid resistance.

$-254 \mathrm{C}>\mathrm{G}$ localizes within the promoter region of the TRPC6 gene, which contains several transcription binding sites, such as nuclear factor of activated T cells $(19,20)$. In cardiomyocytes, TRPC6 was upregulated through the calcineurin-nuclear factor of activated $\mathrm{T}$ cells signaling pathway leading to cardiac 
a
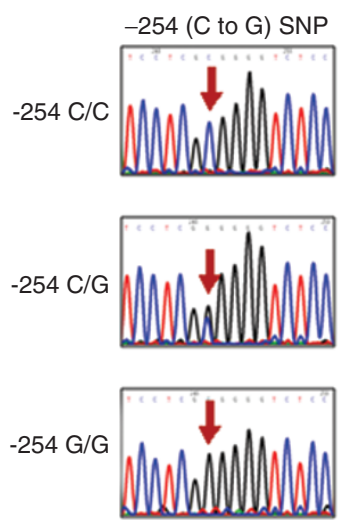
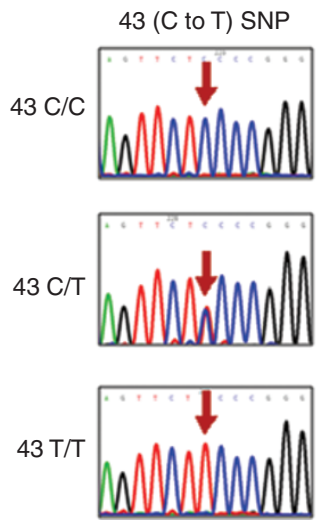
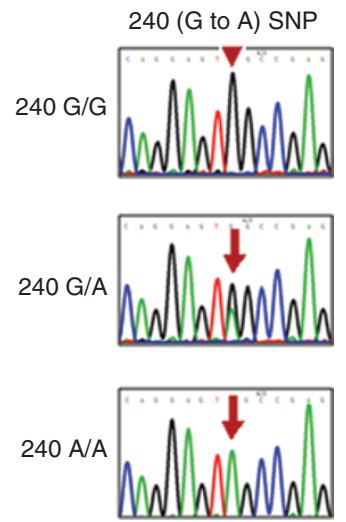

b
$-305$
CAGCGGCCCCGCCTGTGCCCTCTCTGCCCGGGCGCCCCAGACGCATCCTC -256
$-255$
GCGGGGTCTCCTCGGCCTGACCTGCTCAGGTCAAGATCCTCTTTGCACCC -206
G -254 (C-to-G)
-205 CCTTAAGTGGTGACTTTTCCCCGGGCCAGTGGGCGAGCCACTTGCGGCGG -156
-155 GCGTCTGCACCCCCTGCTTCACCGTCGTCCCCTGGGCACCGGTCTGCCCA -106
-105 GGTCCAGTTCGGCCGCTGACGCGAACCCTCCGCACCGGGTCCCCGCTGGA -56
-55 ACTGCCCACTCGGCTCCCCGGGAGCGGGGCCCAGGCCAGTCGGGCGTT -7
-6 CCCGCCATGAGCCAGAGCCCGGCGTTCGGGCCCCGGAGGGGCAGTTCTCC 44
P15S (C-to-T) T
45 CCGGGGCGCTGCCGGAGCCGCTGCGCGGCGCAACGAGAGCCAGGACTATC 94
95 TGCTCATGGACTCGGAGCTGGGAGAAGACGGCTGCCCGCAAGCCCCGCTG 144
145 CCTTGCTACGGCTACTACCCCTGCTTGTGAGTGCCGGCGACGCGGGGCGG 194
195 ATCGGGCGCGGGCTGCGCGGAGGGAGGTTGTGCGCTCGCAGGAGTGGCCG 244
240 (G-to-A) A

245 AGTCCGTCCGCGCGCGTCCTGAACCCGCGTGTGTACCTCCTAGGACGGTG 294

Figure 1. Identification of three single-nucleotide polymorphisms (SNPs) in the human transient receptor potential channel 6 gene. (a) Sequence chromatographs for the three SNPs in steroid-sensitive nephrotic syndrome and steroid-resistant nephrotic syndrome patients. Genomic DNA extracted from peripheral blood lymphocytes of patients was subjected to polymerase chain reaction to detect the molecular alterations of TRPC6. DNA sequencing analysis of all coding exons demonstrated the following mutations: $-254 \mathrm{C}>\mathrm{G}, 43 \mathrm{C}>\mathrm{T}$, and $240 \mathrm{G}>\mathrm{A}$ (shown as red arrows). (b) The location of the three SNPs, $-254(C>G),+43(C>T)$, and $+240(G>A)$. Green represents the coding region in exon 1 . The blue letters $C$ and $G$ represent the original sequence, and the red letters $G, T$, and $A$ represent the mutational bases.

Table 2. Allele frequency comparison of three SNPs between SSNS and SRNS groups

\begin{tabular}{|c|c|c|c|c|c|c|}
\hline SNP & Genotype & Allele & SSNS $(n=23), n(\%)$ & SRNS $(n=28), n(\%)$ & Odds ratio $(95 \% \mathrm{Cl})$ & $P$ value \\
\hline \multirow[t]{2}{*}{-254} & C to $\mathrm{G}$ & C & $32(72.9)$ & $28(59.5)$ & $2.29(1.01-5.18)$ & 0.046 \\
\hline & & G & $14(27.1)$ & $28(40.5)$ & - & \\
\hline+43 & & $\mathrm{~T}$ & $4(8.3)$ & $5(8.1)$ & - & \\
\hline+240 & $\mathrm{G}$ to $\mathrm{A}$ & G & $36(75.0)$ & $36(68.9)$ & $2.00(0.82-4.86)$ & 0.12 \\
\hline
\end{tabular}

$\mathrm{Cl}$, confidence interval; SNP, single-nucleotide polymorphism; SRNS, steroid-resistant nephrotic syndrome; SSNS, steroid-sensitive nephrotic syndrome.

$P$ values, odds ratios, and $95 \% \mathrm{Cls}$ are calculated by $X^{2}$ analysis for $2 \times 2$ contingency tables.

hypertrophy (20). TRPC6 mutations in the familial forms of FSGS have been shown to activate basal nuclear factor of activated $\mathrm{T}$ cells-mediated transcription significantly compared with wild-type TRPC6 (19). Yu et al. revealed that a higher frequency of $-254 \mathrm{G}$ was associated with the development of idiopathic pulmonary arterial hypertension (21) and demonstrated that it modulates TRPC6 gene promoter activity. In addition, $\mathrm{Yu}$ et al. showed that the $-254 \mathrm{G}$ allele enhanced TNF- $\alpha$ - and NF- $\kappa B-$ mediated TRPC6 transcription (21), indicating that this variant had the potential to modulate TRPC6 
Table 3. Genotype comparison of three SNPs between SSNS and SRNS groups

\begin{tabular}{|c|c|c|c|c|c|c|c|c|c|}
\hline Position & SNP & SSNS $(n=23)(\%)$ & SRNS $(n=28) ; n(\%)$ & \multicolumn{2}{|c|}{ Dominant model } & \multicolumn{2}{|c|}{ Recessive model } & \multicolumn{2}{|c|}{ Additive model } \\
\hline \multirow[t]{2}{*}{-254} & $\mathrm{C} / \mathrm{C}$ & $12(52.2)$ & $7(25.0)$ & $3.27(1.00-10.69)$ & 0.046 & $2.22(0.50-9.81)$ & 0.48 & $1.00(0.27-3.74)$ & $1.00^{\mathrm{a}}$ \\
\hline & $\mathrm{G} / \mathrm{G}$ & $3(13.0)$ & $7(25.0)$ & & & & & $4.00(0.77-20.68)$ & $0.13^{c}$ \\
\hline \multirow[t]{2}{*}{+43} & $\mathrm{C} / \mathrm{C}$ & $19(82.6)$ & $24(85.7)$ & $0.79(0.18-3.59)$ & 1.00 & $1.03(0.97-1.11)$ & 1.00 & $1.00(0.43-2.34)$ & $1.00^{\mathrm{a}}$ \\
\hline & $\mathrm{T} / \mathrm{T}$ & $0(0.0)$ & $1(3.6)$ & & & & & $1.04(0.96-1.13)$ & $1.00^{c}$ \\
\hline \multirow[t]{3}{*}{+240} & $\mathrm{G} / \mathrm{G}$ & $14(58.3)$ & $12(51.4)$ & $2.07(0.68-6.38)$ & 0.20 & $3.67(0.38-35.36)$ & 0.36 & $1.00(0.34-2.98)$ & $1.00^{\mathrm{a}}$ \\
\hline & $\mathrm{G} / \mathrm{A}$ & $8(33.3)$ & $12(35.1)$ & & & & & $1.75(0.54-5.70)$ & $0.35^{\mathrm{b}}$ \\
\hline & $\mathrm{A} / \mathrm{A}$ & $1(8.4)$ & $4(13.5)$ & & & & & $4.67(0.46-47.63)$ & $0.33^{c}$ \\
\hline
\end{tabular}

$\mathrm{Cl}$, confidence interval; SNP, single-nucleotide polymorphism; SRNS, steroid-resistant nephrotic syndrome; SSNS, steroid-sensitive nephrotic syndrome.

$P$ values, odds ratios, and $95 \% \mathrm{Cl}$ are calculated by $X^{2}$ analysis for comparison of the genotype frequencies between SSNS patients and SRNS subjects.

aThe normal homozygotes were the control, e.g., SNP -254C/G (C/C vs. C/C). ' Heterozygotes vs. homozygotes, e.g., SNP -254C/G (C/G vs. C/C). c SNP homozygotes vs. normal homozygotes, e.g., SNP -254C/G (G/G vs. C/C).

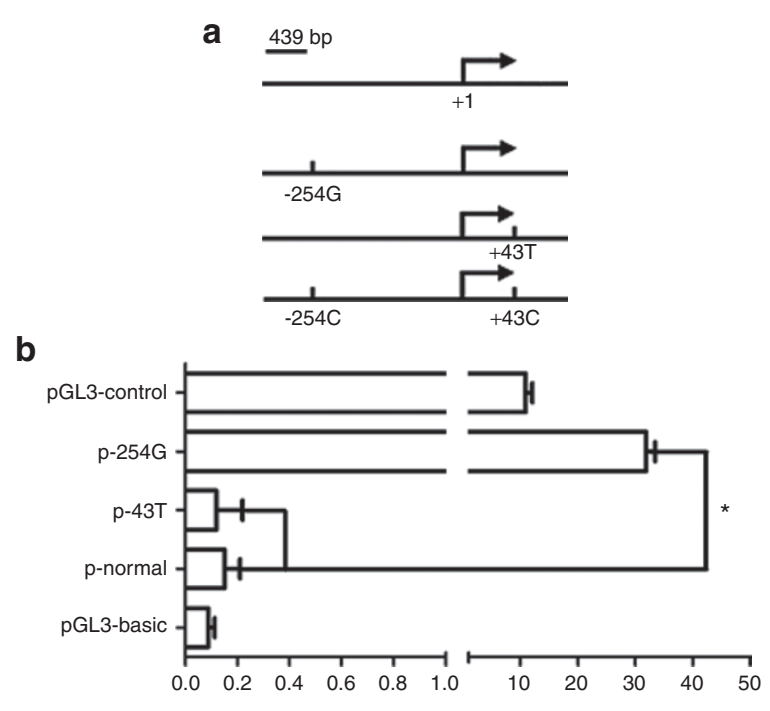

Figure 2. Effect of TRPC6 mutations on transient receptor potential channel 6 promoter activation in podocytes. (a) Schematic diagram of a series of plasmids used for the promoter assay. 439-bp DNAs from TRPC6 promoter region, containing three variants $(-254 \mathrm{G},+43 \mathrm{~T}$, and normal), were subcloned into luciferase expression plasmids. The transcription start site is denoted by +1 and indicated by a horizontal arrow. (b) $-254 \mathrm{G}$ allele ( $p-254 \mathrm{G})$ significantly enhanced the TRPC6 promoter activation. Podocytes cotransfected with the different pGL3 plasmids ( $p-254 G$, p-43T, p-normal, pGL3-control, and pGL3-basic) and the pRL-SV40 vector. Luciferase activity was determined in the cell transfection studies. The results were expressed as the ratio of firefly to Renilla luciferase activity of quadruplicate cultures, representative of three experiments. ${ }^{*} P<0.0001$; luciferase activity of $\mathrm{p}-254 \mathrm{G}$ compared with that of $\mathrm{p}-43 \mathrm{~T}$ and $\mathrm{p}$-normal, respectively.

expression in response to immune or inflammatory stress. We found this variant significantly enhanced the activity of the TRPC6 promoter in podocytes (Figure 2). Furthermore, we determined that there was increased expression of TRPC6 in the glomeruli and renal tubules of children with SRNS and that children with the $-254 \mathrm{G}$ allele have a higher expression of a
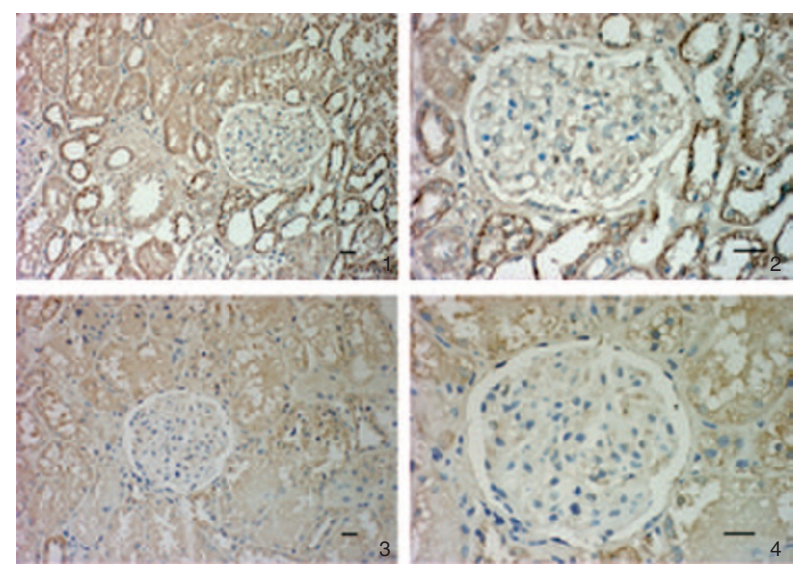

b

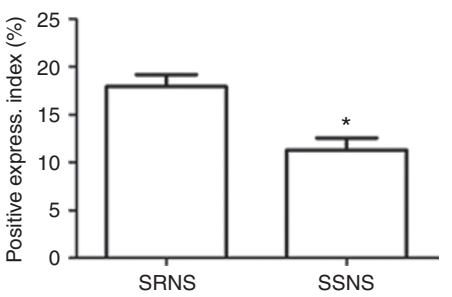

C

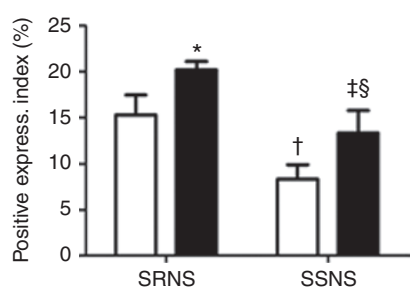

Figure 3. Transient receptor potential channel 6 (TRPC6) protein expression in INS patients. (a) Immunohistochemistry staining of TRPC6 protein expression in renal biopsy specimens of steroid-resistant nephrotic syndrome (SRNS) (1 and 2) and steroid-sensitive nephrotic syndrome (SSNS) ( 3 and 4) patients. Magnification of 1 and 3 is $\times 200$, and magnification of 2 and 4 is $\times 400$, bar $=200 \mu \mathrm{m}$. (b) Comparison of TRPC 6 expression (express.) in renal tubules between SRNS and SSNS children, calculated by the Motic Images Advanced 3.2 medical image quantitative analysis system and software (Motic China Group). The mean of TRPC6 protein expression is higher in SRNS children, ${ }^{*} P=0.01$. (c) Comparison of TRPC6 protein expression in renal tubules between SRNS and SSNS with (black columns) or without (white columns) $-254 \mathrm{C}>\mathrm{G}$ single-nucleotide polymorphism (SNP). The calculation method was the same as that in panel $\mathbf{b}$. Comparison of TRPC 6 expression: ${ }^{*} P=0.047$, between SRNS children with or without $-254 C>G$ SNP; ${ }^{\circledR} P=0.11$, between SSNS children with or without $-254 \mathrm{C}>\mathrm{G} \mathrm{SNP} ;{ }^{\dagger} P=0.07$, for all INS patients without $-254 \mathrm{C}>\mathrm{G}$ SNP; and ${ }^{\ddagger} P=$ 0.01 , for all INS patients with $-254 C>$ G SNP. 
Table 4. Comparison of positive expression index of transient receptor potential channel 6 between SRNS and SSNS children with or without the $-254 \mathrm{C}>\mathrm{G}$ SNP

\begin{tabular}{lcccc}
\hline Group & $-254 \mathrm{C} / \mathrm{C}(n)$ & $\begin{array}{c}-254 \mathrm{C} / \mathrm{G} \\
\text { and } \mathrm{G} / \mathrm{G}(n)\end{array}$ & $P^{\mathrm{a}}$ & Total $(n)$ \\
\hline SSNS & $8.32 \pm 1.60(9)$ & $13.31 \pm 2.45(4)$ & 0.11 & $11.28 \pm 1.27(13)$ \\
SRNS & $15.28 \pm 2.16(6)$ & $20.19 \pm 0.90(10)$ & 0.047 & $17.90 \pm 1.26(16)$ \\
$P^{\mathrm{b}}$ & 0.07 & 0.01 & - & 0.001 \\
\hline
\end{tabular}

SNP, single-nucleotide polymorphism; SRNS, steroid-resistant nephrotic syndrome; SSNS, steroid-sensitive nephrotic syndrome.

a $P$ value for SSNS (-254C/C vs. -254C/G and G/G) and SRNS (-254C/C vs. - $254 C / G$ and $\mathrm{G} / \mathrm{G}) .{ }^{b} P$ value for SSNS vs. SRNS with genotype $-254 \mathrm{C} / \mathrm{C},-254 \mathrm{C} / \mathrm{G}$ and $\mathrm{G} / \mathrm{G}$, and the total.

TRPC6 in both the SRNS and SSNS groups (Figure 3). Taken together, our data showed that the -254C > G SNP may contribute to the upregulation of TRPC6 transcription and protein expression during the development of steroid resistance.

TRPC6 is a TRP family calcium channel that mediates calcium influx in response to phospholipase C activation $(22,23)$ and the secondary messenger diacylglycerol (24). It has been demonstrated that the elevated expression of TRPC6 could induce podocyte depletion from the glomerulus and lead to proteinuria with the histological features of FSGS in the transgenic animal model (25). Gain-of-function mutations in TRPC6 led to the constitutive activation of the calcineurin-nuclear factor of activated $\mathrm{T}$ cells pathway, which influences actin dynamics in podocytes through the degradation of synaptopodin (19). Therefore, the upregulation of TRPC6 expression results in a higher calcium influx $(8,14,17)$ and actin reorganization in podocytes, finally leading to proteinuria $(11,26)$. Therefore, either the increased expression or increased function of TRPC6 is associated with crucial pathways that influence the podocyte phenotype. In addition to the transcription-promoting activity, $-254 \mathrm{C}>\mathrm{G}$ significantly increased basal $\left[\mathrm{Ca}^{2+}\right]_{\text {cyt }}$ and agonist-triggered $\mathrm{Ca}^{2+}$ entry into pulmonary artery smooth muscle cells (21). Here, we propose that in podocytes, $-254 \mathrm{G}$ allele might contribute to the susceptibility of podocytes to injuries and resistance to medications through enhancing the expression and function of TRPC6, which probably leads to the deterioration of INS.

The present study comprised 51 children of INS and indicated a close relationship between the $-254 \mathrm{C}>\mathrm{G}$ in TRPC6 gene and SRNS. Although the TRPC6 variants were shown in a small group of INS patients in China, we can still speculate that this variant increased the susceptibility of steroid resistance development in pediatric INS in China. To our knowledge, the mechanism of $-254 \mathrm{C}>\mathrm{G}$ in regulation of TRPC6 gene is not so clear, the SNP might not act independently; it might be associated with the other unknown variants to effect together or it is merely a component of the pathway to adjust the individual sensitivity to the hormone. Therefore, large cohorts in whom both gene prevalence and functional studies were conducted are needed to confirm our findings.

Altogether, our findings in this study provided new evidence for the association between TRPC6 SNPs and steroid sensitivity in SRNS children. The genetic variations of TRPC6 may underlie the mechanism of nephrotic syndrome. -254C>G, a SNP underlying enhanced TRPC6 transcription and expression, may correlate with the development of steroid resistance in Chinese children with nephrotic syndrome. As we know, most TRPC6 mutations are found in adult FSGS patients, but in clinical work, children who have repeated renal biopsy show a transition process from minimal change nephrotic syndrome to FSGS (27). Our study explored a promising possibility of TRPC6 mutation as a biomarker; it can help clinicians to know a potential response to steroids of the patients and consequently adjust the therapeutic response.

\section{METHODS}

\section{Patients}

Fifty-one patients with INS hospitalized in the Children's Hospital of Fudan University from 2009 to 2010 were enrolled in the study. According to their response to steroid therapy, the patients were divided into two groups: steroid-sensitive (SSNS) and steroid-resistant (SRNS). INS was defined as a condition with heavy proteinuria (urinary protein excretion $\geq 40 \mathrm{mg} / \mathrm{m}^{2} \cdot \mathrm{h}$ ) with hypoalbuminemia $\leq 25 \mathrm{~g} / \mathrm{l}$ and without evidence of secondary nephrotic syndrome. Steroidresistant condition was defined as the failure to achieve remission despite $4 \mathrm{wk}$ of prednisolone induction $(2 \mathrm{mg} / \mathrm{kg} \cdot \mathrm{d})$. Twenty-four out of 28 cases with SRNS and 13 out of 23 cases with SSNS were subjected to renal biopsy. This study was certified by the Ethics Committee of Fudan University, with written, informed consent signed by the parents/legal guardians of all children.

\section{SNP Analysis}

Genomic DNA was isolated from peripheral leukocytes using the TIANamp Blood DNA Kit (TIANgene, Beijing, China). The exons of TRPC6 and the exon-intron flanking sequences were amplified by polymerase chain reaction (8) and analyzed by direct sequencing (Invitrogen, Carlsbad, CA).

\section{Immunohistochemistry}

The expression of TRPC6 in the glomerulus of the patients was illustrated by immunohistochemistry staining. The renal biopsy specimens were provided by the Pathology Center of Fudan University. Briefly, 3- $\mu \mathrm{m}$ thick sections were deparaffinized, treated with $3 \%$ $\mathrm{H}_{2} \mathrm{O}_{2}$ (in methanol) to inactivate the endogenous HRP, and subjected to antigen retrieval in a microwave oven in sodium citrate buffer $(\mathrm{pH}$ 6.0). Then, the slides were blocked for $30 \mathrm{~min}$ at $37^{\circ} \mathrm{C}$ in $5 \%$ goat serum albumin and incubated with rabbit anti-TRPC6 antibodies (dilution 1:100, Abcam, Cambridge, England) overnight at $4{ }^{\circ} \mathrm{C}$ and peroxidase-conjugated goat anti-rabbit IgG for $45 \mathrm{~min}$ at $37^{\circ} \mathrm{C}$. The signal was developed by applying 3,3'-diaminobenzidine substrate purchased from Sigma Aldrich, St. Louis, MO, and the sections were counterstained with Meyer's hematoxylin. After mounting, the sections were observed under light microscopy. The Motic Images Advanced 3.2 medical image quantitative analysis system and software (Motic China Group, Xiamen, China) were used to measure the expression of TRPC6. TRPC6 expression of each biopsy specimen were captured, analyzed, and calculated. The mean positive index (\%) of five representative fields for each sample was the final index.

\section{Cell Culture}

Immortalized mouse podocytes were maintained in RPMI 1640 supplemented with $10 \%$ fetal bovine serum in the presence of $50 \mathrm{U} / \mathrm{ml}$ of interferon- $\gamma$ at $33{ }^{\circ} \mathrm{C}$ in $5 \% \mathrm{CO}_{2}$ for $5 \mathrm{~d}$ and then differentiated at $37^{\circ} \mathrm{C}$ in $10 \%$ RPMI 1640 in the absence of interferon- $\gamma$ for $14 \mathrm{~d}(28)$.

\section{TRPC6 Promoter Construction}

The plasmids of TRPC6 promoter region $(-335$ to +104 ; $\mathrm{p}$-254-Luc, $\mathrm{p}-43$-Luc, and p-normal-Luc) were generated based on the protocol from Yu et al. (21). The control plasmids, pGL3-control (positive control) and pGL3-basic (negative control), were purchased from Promega (Madison, WI). 


\section{Luciferase Reporter Assay}

Transfection of plasmid DNA was carried out with Lipofectamine 2000 Transfection Reagent (Invitrogen) as recommended by the manufacturer. Briefly, podocytes plated in 24-well plates were cotransfected with $490 \mathrm{ng}$ of different pGL3 plasmids and $10 \mathrm{ng}$ of the pRL-SV40 vector (Promega), an internal control plasmid. The cells were lysed $16 \mathrm{~h}$ after transfection, and the luciferase activities in cell lysates were quantified using Dual-Luciferase Reporter Assay System (Promega) and a Lumat LB 9507 (Berthold Technologies, Bad Wildbad, Germany). The relative luciferase activity was expressed as the ratio of firefly to Renilla luciferase activities of quadruplicate cultures, representative of three independent experiments.

\section{Statistical Analysis}

The data were expressed as mean \pm SD. Using SPSS version 17.0 software, statistical differences of measurement data were assessed with an unpaired Student's $t$-test. The $\chi^{2}$ test and Fisher's exact test were used to analyze the differences in the allele frequencies and genotype frequencies, respectively, between groups. The odds ratio and the $95 \%$ confidence interval in each comparison were assessed in a dominant model (e.g., CC vs. CG + GG), a recessive model (e.g., CC + CG vs. GG), and an additive model (e.g., CC vs. CC, CC vs. CG, and CC vs. GG). Differences were considered significant at values of $P<0.05$.

\section{SUPPLEMENTARY MATERIAL}

Supplementary material is linked to the online version of the paper at http:// www.nature.com/pr

\section{ACKNOWLEDGMENTS}

We thank all the children who participated in the study. We also thank XiaoXin Xu (Xin Hua Hospital Affiliated to Shanghai Jiao Tong University School of Medicine) and Nai-Qing Zhao (Department of Health Statistics, Public Health College of Fudan University) for their contributions and guidance in the statistical analysis.

\section{STATEMENT OF FINANCIAL SUPPORT}

This work was supported by the Chinese National Nature Science Foundation (30871177 to W.-Y.H.) and Shanghai Health Bureau Foundation (XBR 2011010 to W.-Y.H.).

Disclosure: None of the authors has any conflicts of interest to disclose.

\section{REFERENCES}

1. Khurana M, Traum AZ, Aivado M, et al. Urine proteomic profiling of pediatric nephrotic syndrome. Pediatr Nephrol 2006;21:1257-65.

2. Kitiyakara C, Kopp JB, Eggers P. Trends in the epidemiology of focal segmental glomerulosclerosis. Semin Nephrol 2003;23:172-82.

3. Collins AJ, Foley RN, Chavers B, et al. United States Renal Data System 2011 Annual Data Report: Atlas of chronic kidney disease \& end-stage renal disease in the United States. Am J Kidney Dis 2012; 59:A7, e1-e420.

4. Kitiyakara C, Eggers P, Kopp JB. Twenty-one-year trend in ESRD due to focal segmental glomerulosclerosis in the United States. Am J Kidney Dis 2004;44:815-25.

5. Ulinski T, Aoun B. Pediatric idiopathic nephrotic syndrome: treatment strategies in steroid dependent and steroid resistant forms. Curr Med Chem 2010;17:847-53.

6. McBryde KD, Kershaw DB, Smoyer WE. Pediatric steroid-resistant nephrotic syndrome. Curr Probl Pediatr Adolesc Health Care 2001;31:280307.

7. Ehrich JH, Geerlings C, Zivicnjak M, Franke D, Geerlings H, Gellermann J. Steroid-resistant idiopathic childhood nephrosis: overdiagnosed and undertreated. Nephrol Dial Transplant 2007;22:2183-93.
8. Winn MP, Conlon PJ, Lynn KL, et al. A mutation in the TRPC6 cation channel causes familial focal segmental glomerulosclerosis. Science 2005;308:1801-4.

9. Machuca E, Benoit G, Antignac C. Genetics of nephrotic syndrome: connecting molecular genetics to podocyte physiology. Hum Mol Genet 2009;18(R2):R185-94.

10. Mukerji N, Damodaran TV, Winn MP. TRPC6 and FSGS: the latest TRP channelopathy. Biochim Biophys Acta 2007;1772:859-68.

11. Benoit G, Machuca E, Nevo F, Gribouval O, Lepage D, Antignac C. Analysis of recessive $\mathrm{CD} 2 \mathrm{AP}$ and ACTN4 mutations in steroid-resistant nephrotic syndrome. Pediatr Nephrol 2010;25:445-51.

12. Antignac C. Molecular basis of steroid-resistant nephrotic syndrome. Nefrologia 2005;25 Suppl 2:25-8.

13. Reusz G, Szabó A, Fekete A. [Nephrotic syndrome in childhood]. Orv Hetil 2006;147:2251-60.

14. Reiser J, Polu KR, Möller CC, et al. TRPC6 is a glomerular slit diaphragmassociated channel required for normal renal function. Nat Genet 2005;37:739-44.

15. Santín S, Ars E, Rossetti S, et al.; FSGS Study Group. TRPC6 mutational analysis in a large cohort of patients with focal segmental glomerulosclerosis. Nephrol Dial Transplant 2009;24:3089-96.

16. Heeringa SF, Möller CC, Du J, et al. A novel TRPC6 mutation that causes childhood FSGS. PLoS ONE 2009;4:e7771.

17. Zhu B, Chen N, Wang $\mathrm{ZH}$, et al. Identification and functional analysis of a novel TRPC6 mutation associated with late onset familial focal segmental glomerulosclerosis in Chinese patients. Mutat Res 2009;664: $84-90$.

18. Gigante M, Caridi G, Montemurno E, et al. TRPC6 mutations in children with steroid-resistant nephrotic syndrome and atypical phenotype. Clin J Am Soc Nephrol 2011;6:1626-34.

19. Schlöndorff J, Del Camino D, Carrasquillo R, Lacey V, Pollak MR. TRPC6 mutations associated with focal segmental glomerulosclerosis cause constitutive activation of NFAT-dependent transcription. Am J Physiol, Cell Physiol 2009;296:C558-69.

20. Kuwahara K, Wang Y, McAnally J, et al. TRPC6 fulfills a calcineurin signaling circuit during pathologic cardiac remodeling. J Clin Invest 2006;116:3114-26.

21. Yu Y, Keller SH, Remillard CV, et al. A functional single-nucleotide polymorphism in the TRPC6 gene promoter associated with idiopathic pulmonary arterial hypertension. Circulation 2009;119:2313-22.

22. Clapham DE. TRP channels as cellular sensors. Nature 2003;426:517-24.

23. Okada T, Inoue R, Yamazaki K, et al. Molecular and functional characterization of a novel mouse transient receptor potential protein homologue TRP7. $\mathrm{Ca}(2+)$-permeable cation channel that is constitutively activated and enhanced by stimulation of $\mathrm{G}$ protein-coupled receptor. J Biol Chem 1999;274:27359-70.

24. Hofmann T, Obukhov AG, Schaefer M, Harteneck C, Gudermann T, Schultz G. Direct activation of human TRPC6 and TRPC3 channels by diacylglycerol. Nature 1999;397:259-63.

25. Krall P, Canales CP, Kairath P, et al. Podocyte-specific overexpression of wild type or mutant trpc6 in mice is sufficient to cause glomerular disease. PLoS ONE 2010;5:e12859.

26. Mir S, Yavascan O, Berdeli A, Sozeri B. TRPC6 gene variants in Turkish children with steroid-resistant nephrotic syndrome. Nephrol Dial Transplant 2012;27:205-9.

27. Cho MH, Hong EH, Lee TH, Ko CW. Pathophysiology of minimal change nephrotic syndrome and focal segmental glomerulosclerosis. Nephrology (Carlton) 2007;12 Suppl 3:S11-4.

28. Shankland SJ, Pippin JW, Reiser J, Mundel P. Podocytes in culture: past, present, and future. Kidney Int 2007;72:26-36. 